\title{
Frontal Behavioral Inventory: Diagnostic Criteria for Frontal Lobe Dementia
}

\author{
Andrew Kertesz, Wilda Davidson and Hannah Fox
}

\begin{abstract}
Objective: To utilize the diagnostic criteria of frontal lobe dementia (FLD). Methods: We studied 12 patients with FLD diagnosed clinically, with radiological confirmation in 10 and autopsy confirmation in 2; sixteen patients with Alzheimer's disease matched for stage and severity to FLD and 11 patients with depressive dementia were used as control groups. A 24-item Frontal Behavioral Inventory (FBI) using the most relevant behavioral manifestations of FLD was administered in these populations. Results: FLD patient scores on the FBI were much higher compared with control groups (AD and DD). Item analysis showed loss of insight, indifference, distractibility, personal neglect and apathy as the most frequent negative symptoms. Perseveration, disinhibition, inappropriateness, impulsivity, and irresponsibility were the most significant positive symptoms. An operational definition of FLD included a minimum FBI score of 27 . Only one false positive was shown in the depressive group and none among the AD group, indicating little overlap between patient groups, and a high discriminating value of the FBI. Conclusions: The FBI appears to be a useful diagnostic instrument and a method to operate the behavioral criteria of FLD. Further prospective studies are warranted to establish validity.
\end{abstract}

\begin{abstract}
RÉSUMÉ: Évaluation du comportement frontal: Critères diagnostiques de la démence frontale. Objectif: De rendre opérationnels les critères diagnostiques de la démence frontale (DF). Méthodes: Nous avons étudié 12 patients atteints de DF diagnostiquée cliniquement, avec confirmation radiologique du diagnostic chez 10 et autopsique chez 2; 16 patients atteints de la maladie d'Alzheimer (MA) appariés pour le stade et la sévérité de la DF et 11 patients atteints d'une démence dépressive (DD) ont servi de contrôles. Une grille d'évaluation du comportement frontal (ÉCF) comportant 24 items ciblant les manifestations du comportement les plus pertinentes à la DF a été administrée à ces patients. Résultats: Les scores des patients atteints de DF à l'ÉCF étaient beaucoup plus élevés comparés à ceux des groupes contrôles (MA et DD). L'analyse par item a monté une perte de la capacité d'introspection, de l'indifférence, de la distractivité, de la négligence de leur personne et de l'apathie comme symptômes négatifs les plus fréquents. La persévération, la désinhibition, l'inopportunité, l'impulsivité et l'irresponsabilité étaient les symptômes positifs les plus significatifs. Une définition opérationelle de la DF incluait un score minimun de 27 à l'ÉCF. On a constaté un seul faux positif dans le groupe DD et aucun dans le groupe MA, ce qui indique qu'il y a peu de chevauchement entre les groupes de patients et que la valeur discriminante de l'ÉCF est élevée. Conclusions: L'ÉCF semble être un outil diagnostique utile et une méthode pour rendre opérationnels les critères comportementaux de la DF. Des études prospectives sont justifiées pour en établir la validité.
\end{abstract}

Can. J. Neurol. Sci. 1997; 24: 29-36

Frontal lobe dementia (FLD) has been distinguished from Alzheimer's disease (AD) by clinical, neuroimaging, and pathological features. ${ }^{1,2}$ The clinical features of FLD resemble closely those of Pick's disease and often overlap with reported cases of primary progressive aphasia (PPA). ${ }^{3,4}$ In addition, the association of these conditions with motor neuron disease ${ }^{5,6}$ and the similarity of pathology in corticobasal ganglionic degeneration $(\mathrm{CBGD})^{7,8}$ suggested a biological relationship between these entities we called "Pick complex". 4

The clinical diagnosis of FLD depends on the prominence of personality changes and behavioral alterations that are characteristic of frontal lobe disease. A consensus has been achieved by the Lund and Manchester groups ${ }^{9}$ concerning the main features of what they began to call frontotemporal dementia (FTD). The core diagnostic features of FTD were listed as early loss of personal hygiene, social awareness, disinhibition, mental rigidity and inflexibility, hyperorality, perseverative behavior, utilization behavior, distractibility, and loss of insight. Affective symptoms were: indifference, remoteness, inertia, and aspontaneity. Reduction of speech, and finally mutism, was also considered common. In addition, preserved spatial function and the absence of severe amnesia were notable. The consensus criteria also included neuropathological and neuroimaging features.

From the Department of Clinical Neurological Sciences, St. Joseph's Health Centre, University of Westem Ontario, London.

RECEIVED JUNE 4, 1996. ACCEPTED IN FINAL FORM AUGUST 29, 1996

Reprint requests to: Dr. A. Kertesz. Division of Neurology. St. Joseph's Health Centre. 268 Grosvenor Street, London, Ontario, Canada N6A 4V2 
The purpose of this study is to operationalize the behavioral criteria in FLD by constructing a frontal behavioral inventory (FBI), which is based partly on the consensus statement from Manchester/Lund and partly on our experience with 12 patients with FLD. These patients with the predominantly behavioral disorder of FLD are quite distinct from the PPA cases initially. ${ }^{4,10}$ The clinical presentation in PPA is aphasic, but as the disease progresses, behavioral changes often become evident. Conversely, although behavioral presentation can be striking initially, logopenia, aphasia and mutism often develop later in FLD. The pathology seems similar in FLD and PPA, suggesting that these two types of presentation belong to the same disease entity, lately termed FTD. Nevertheless, a behavioral inventory for FLD may be helpful for diagnosis and characterization of the development of the disease. It may be helpful in associated disorders such as corticobasal ganglionic degeneration (CBGD) and FLD, and PPA with amytrophic lateral sclerosis (ALS), all of which have "Pick complex" or Pick variant pathology or features of clinical Pick's disease that may include frontal behavioral changes. Furthermore, the FBI may be helfpul in differentiating the "depressed" and the disinhibited variety of FLD as these patients may score differently on the negative and the disinhibition items.

\section{MethoDS}

A 24-item inventory was constructed to target the most specific behaviors or personality changes that might be elicited on a direct questionnaire, to achieve optimum diagnostic accuracy for FLD. Items were selected from the core diagnostic features of the Lund/Manchester criteria and the most common of symptoms in our FLD patients. In addition, a few items were included to capture specific motor and speech behaviors that may be associated with FLD, such as alien hand, utilization behavior, logopenia, and verbal apraxia. The inventory was designed as a series of structured and scripted questions to be asked of the care-giver (Appendix I). It was usually administered independently by another physician or psychologist while the patient was examined neurologically and neuropsychologically. It was emphasized that a change in behavior or personality was being questioned, not a lifelong personality aberration, although those were separately noted. If the care-giver did not seem to understand the question as it was constructed then an elaboration was encouraged and a different question related to the same target was asked. Each item was scored on a scale of 4 , i.e., $0=$ none; $1=$ mild or occasional, $2=$ moderate, $3=$ severe or most of the time.

The items represent two main types of behavior. The first group of items consists of mainly negative behaviors or lacking certain normal behaviors. The second group pertains to items of disinhibition that usually result in some excess or abnormal behaviors. Negative items included: apathy, aspontaneity, emotional indifference, inflexibility, concreteness, perseveration, distractibility (disorganization), inattention, loss of insight, logopenia, and verbal apraxia. Items of disinhibition included: alien hand, perseveration, disinhibition (irritability), jocularity, irresponsibility (poor judgment), inappropriateness (social), impulsivity, euphoria (restlessness), aggression, hyperorality, hypersexuality, utilization behavior, and incontinence. The items in brackets are modifications or additions since this pilot study was initiated. For example, disinhibition was an original item, since it refers to many similar behaviors it was replaced by irritability, a more specific item for final questionnaire. Alien hand is a feature that may be detected on neurological examination but it was included in the questionnaire since it may be intermittent behavior, not apparent on examination only, and an early sign of CBGD. The last five items represent behaviors usually seen at the later stages of severe frontal lobe illness and represent striking and disturbing abnormalities. They are also the most sensitive to talk about and they are left to the last. Appendix I lists the items with the modifications that differ from the original list of items displayed on the item analysis ( Figure 1a).

In this pilot study, the test was administered to 12 clinically diagnosed FLD patients, 16 patients with Alzheimer's disease (AD) selected for early stages (at presentation to the clinic, community residence with reliable care-giver), and 11 patients with depressive dementia (DD), whose cognitive deficit was considered related to depression by a combined psychiatric, neurological, and neuropsychological evaluation. AD patients met the NINCDS-ADRDA criteria for probable AD and FLD patients the Lund Manchester criteria. ${ }^{9}$ Depressive dementia was defined as the presence of cognitive complaints with a clinical diagnosis of depression. Nine of these patients had depression diagnosed formally by psychiatrists and one had low scores on the Beck Depression Inventory and one was considered depressive because of somatization and memory complaints which could not be confirmed. The severity of the dementia was defined by the scores on the Mattis Dementia Rating Scale (MDRS). The means of these scores between the AD and FLD groups was not significantly different (Table 2). The stage of the illness was defined by the interval between diagnosis and examination (Table 2). FLD patients were selected for this study because of their striking behavioral presentation though at later stages of illness several of them developed a logopenic speech disturbance and one appeared to have typical motor neuron disease as well. Two FLD patients were included retrospectively because of the clinical features and available pathology. The inventory was completed in these two patients using information from the charts. The 12 FLD patients were part of a larger dementia study of 126 typical Alzheimer patients; 15 with probable PPA, 16 with possible PPA, ${ }^{11} 49$ patients with features of vascular dementia (with or without degenerative dementia), 12 patients with depression and dementia (DD), 8 patients with pure progressive memory loss, 8 patients with benign senescent forgetfulness followed for more than 2 years, and others with senectophobia or anxiety who were not demented on the screening test. Three patients, whose clinical features were characteristic of FLD, had vascular disease on neuroimaging and were excluded from the FLD group. Neuroimaging confirmed frontal lobe atrophy in 10/12 patients. Neuroimaging included MRI in eight patients and CT in four patients. Three patients in this series had autopsied confirmation of Pick variant pathology (Pick complex). ${ }^{4}$ The neuropsychological and neuroimaging data on these 12 patients are being prepared for a separate publication.

\section{RESULTS}

The prevalence of symptoms in the history in the 12 FLD patients is tabulated in Table 1 . This frequency table con- 


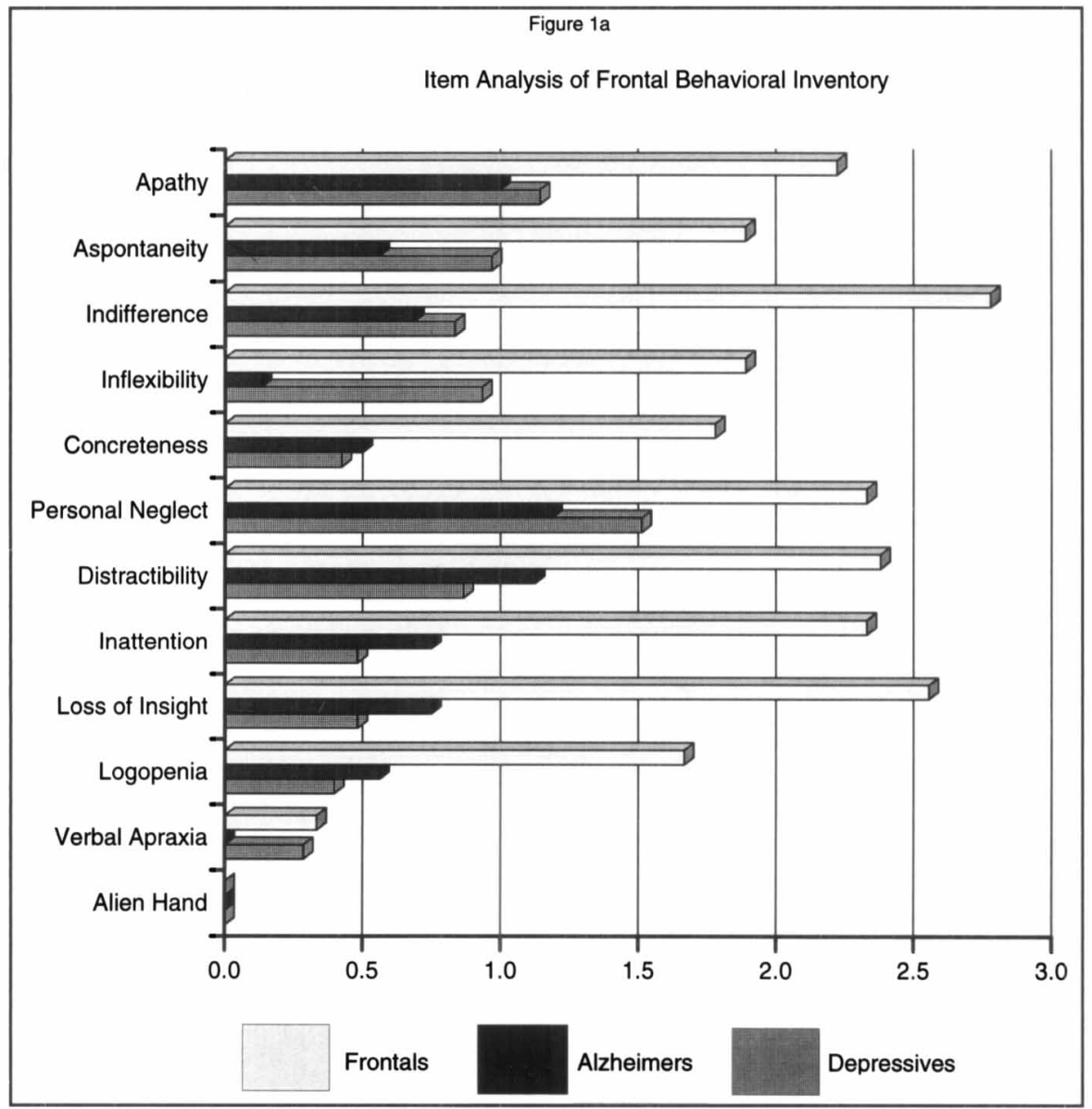

Figure Ia: Item Analysis of Frontal Behavioral Inventory.

tributed to the final selection of items on the FBI. Behaviors occurring in three or more patients $(20 \%)$ were included in the inventory. Some were eliminated because of lack of specificity and others because of overlap with other symptoms. Although forgetfulness was a common complaint, these patients characteristically had normal orientation and some of them performed normally on memory testing. Others exhibited the behavior that is also known as "forgetting to remember," which is related to inattention or lack of motivation to recall specific items. However, it could be shown with formal testing that, in fact, these patients registered these items and with repeated insistence they could recall or at least recognize them from multiple choice (recognition memory preserved). Often neglect of chores, inability to carry out organized, planned, sequential behavior is interpreted as forgetfulness. This, in part, reflects the paucity of lay terms commonly used to describe executive dysfunctions. Unfortunately, even health professionals are willing to accept forgetfulness at face value from history and record it as memory loss. Therefore, it was decided to eliminate forgetfulness from the inventory since it led to false/positive scoring and loss of specificity.
Table 1: The Frequency of Symptoms in 12 Patients on History.

\begin{tabular}{llll}
\hline Lack of insight & $83 \%$ & Aggression & $33 \%$ \\
Inappropriate remarks & $75 \%$ & Hyperorality & $33 \%$ \\
Perseveration & $75 \%$ & Irritability, Impatience & $33 \%$ \\
Logopenia, Anomia & $75 \%$ & Restlessness & $33 \%$ \\
Personal neglect & $66 \%$ & Erratic or reckless driving*** & $33 \%$ \\
Apathy & $58 \%$ & Argumentativeness & $25 \%$ \\
Forgetfulness* & $58 \%$ & Impulsiveness & $25 \%$ \\
Inattention, Distractibility & $58 \%$ & Incontinence & $25 \%$ \\
Indifference & & Aspontaneity & $17 \%$ \\
$\quad$ (Emotional Flatness) & $58 \%$ & Excessive touching & $17 \%$ \\
Disorganization, & & Hypersexuality & $17 \%$ \\
$\quad$ Inability to plan & $50 \%$ & Jocularity ("Moria") & $17 \%$ \\
Social Withdrawal** & $50 \%$ & Kleptomania & $17 \%$ \\
Financial errors*** & $42 \%$ & Childishness & $8 \%$ \\
Mental rigidity, concreteness & $42 \%$ & Emotional lability & $8 \%$ \\
Poor judgment & $42 \%$ & Paranoia & $8 \%$ \\
Rambling* & $42 \%$ & Echolalia & $8 \%$ \\
\hline
\end{tabular}

* Eliminated because of lack of specificity

** Eliminated because of overlap with apathy

*** Overlap with poor judgment or impulsivity

Social withdrawal was another frequent complaint, but it overlapped with apathy and aspontaneity sufficiently that it was 


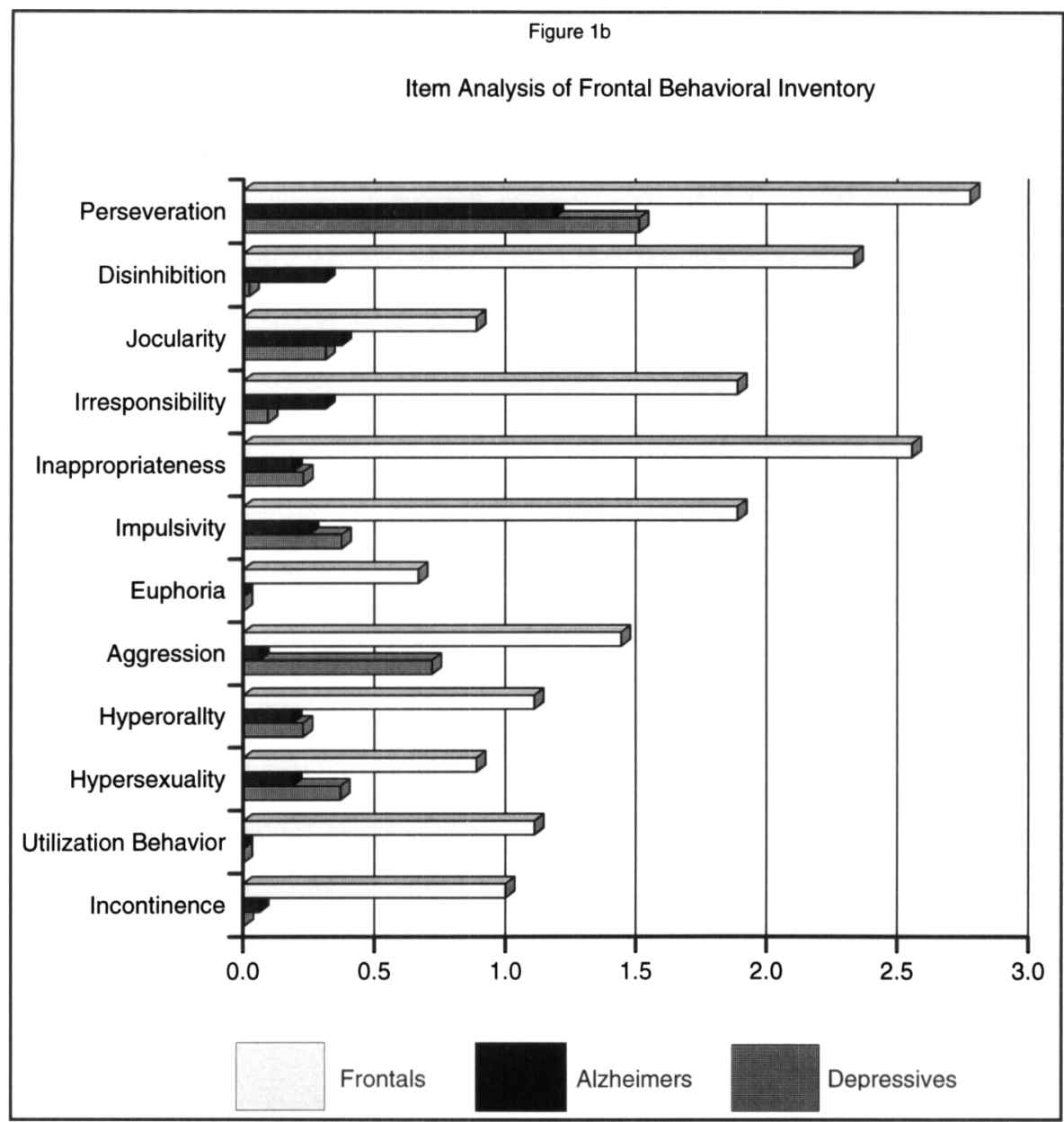

Figure Ib: Item Analysis of Frontal Behavioral Inventory.

not chosen as a separate item. Certain specified behaviors were disturbing, particularly to the care-givers. Some of these, such as erratic or reckless driving, and financial errors overlapped with the more generic category of poor judgment or impulsivity and therefore were included in those, depending on the nature of the errors. Other items, such as rambling, were reported on history with the frequency that would justify their inclusion in the questionnaire, but were eliminated because of lack of specificity and definition. "Rambling" also overlapped to some extent with distractibility and disorganization. Some items, such as aspontaneity, were elicited infrequently on the history but provide a much greater yield when they are asked directly (Figure la). Items, such as hypersexuality, excessive touching (utilization behavior) and inappropriate jocularity were obtained infrequently on the history, as well as on a direct questionnaire. Yet, they were retained among the items because of their high specificity when they did occur. These items would have higher yield if the inventory was used at later stages of the illness.

The demographic features and the comparison of the results of all three groups are presented in Table 2. The FBI scores are significantly higher in the frontal group, compared with the two control groups on ANOVA. On the other hand, no significant differences are found between $\mathrm{AD}$ and DD. A difference in the sex distribution is also seen, as the FLD patients are mostly males. However, more males are in the depressive group also. The age at presentation is different; Alzheimer patients are older

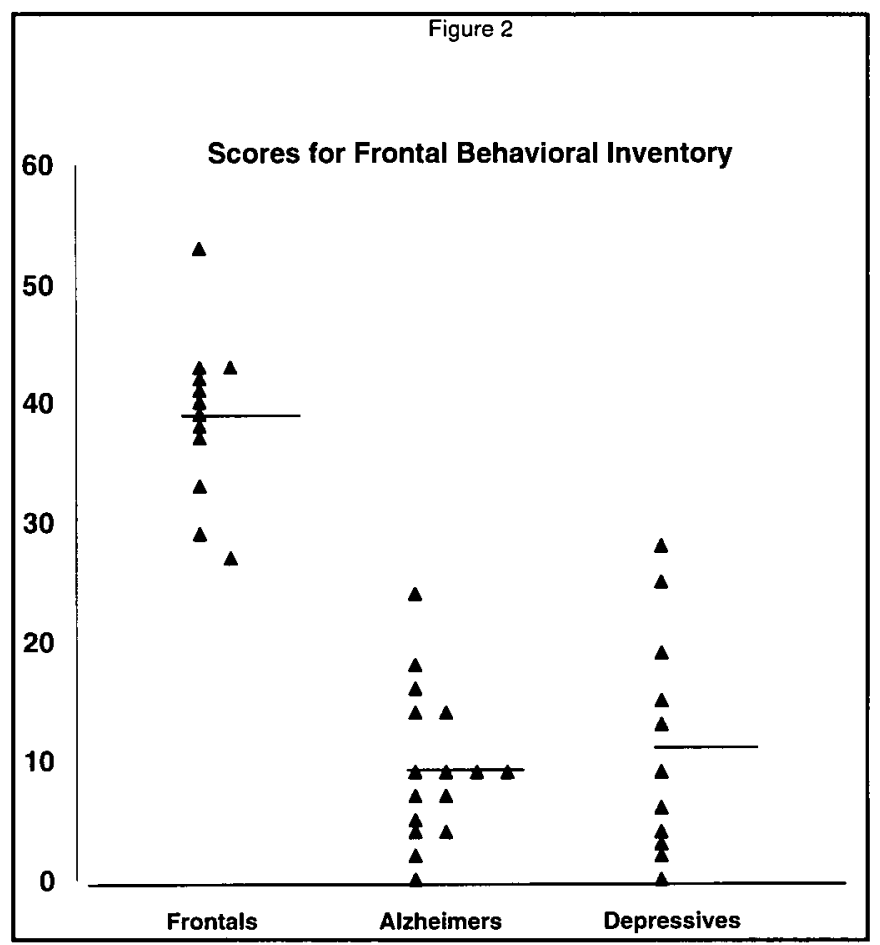

Figure 2: Scores of Frontal Behavioral Inventory. 
Table 2: Frontal Behavioral Inventory.

\begin{tabular}{lccccc}
\hline & \multicolumn{1}{c}{ Sex } & \multicolumn{1}{c}{ Age } & Duration & FBI Score & \multicolumn{1}{c}{ MDRS } \\
\hline Frontals & $\mathrm{M}=10 \quad \mathrm{~F}=2$ & $57.3(10.1)$ & $1.6(.5)$ & $38.8(6.9) *$ & $119.6(15.4)$ \\
Alzheimers & $\mathrm{M}=9 \quad \mathrm{~F}=7$ & $70.9(5.9)^{* *}$ & $2.0(.5)$ & $9.5(6.3)$ & $116.4(10.2)$ \\
Depressives & $\mathrm{M}=8 \quad \mathrm{~F}=3$ & $59.4(13.4)$ & & $11.2(9.6)$ & \\
\hline
\end{tabular}

* F Ratio $=59.8 \mathrm{p}<.000$

$* *$ F Ratio $=7.97 \mathrm{p}<.001$

than the frontal dementias and the depressives. Except one patient, all FLD patients were in the presenile age group.

Figure 1a displays an item analysis consisting of the mean scores of each negative item reflecting the frequency and severity of abnormal behaviors in all three groups. Loss of insight is the most frequently elicited behavior on the questionnaire, and the most prevalent on the history table. This is closely followed by inappropriate remarks, personal neglect and inflexibility. Figure $1 \mathrm{~b}$ represents positive or disinhibition phenomena. Disinhibition, itself, was also included initially but it overlapped with so many other positive phenomena of disinhibition that it was eliminated from the final list of FBI items to avoid duplication. Irritability was substituted as the next specific behavior from the list of complaints by the FLD patients. Some items, such as verbal apraxia received very little positive response, but were kept among the items to detect early speech change in frontotemporal dementia.

A scattergram (Figure 2) shows the individual FBI scores in each group. Very little overlap is seen between the frontal and the depressive groups, and no overlap between the frontal and AD patients. This allows us to determine cutoff points to operationalize the behavioral diagnosis. A practical (sensitive) cutoff point for the diagnosis of FLD is at 27, which includes all FLD scores. Only one false positive is among the depressives. A more conservative cutoff point at 30 would eliminate all false positives and increase specificity. All AD patients and most DD score below 24 , clearly separating the two control groups from FLD. These cutoff points may serve as FBI criteria in grouping patients behaviorally.

\section{Discussion}

More than a hundred behavioral, cognitive, and activities scales are now in the literature. One would be justified to ask the question, "Why yet another behavioral inventory, when there are many in use in a variety of geriatric, and other institutional settings?" The number reflects partly the diversity of need, and partly the complexity of behaviors. Previous behavioral inventories serve a more general purpose exploring abnormal behavior in a geriatric, psychiatric, or general demented population..$^{12-19}$ Several of these including one of the most recent are the Neuropsychiatric Inventory (NPI) by Cummings et al., ${ }^{20}$ have items that overlap with the FBI. However, many questions in the NPI capture behaviors unrelated to frontal deficits and include delusions, hallucinations, dysphoria, anxiety, agitation, etc., some of which in turn overlap, e.g., with BEHAVE-AD designed specifically for AD. ${ }^{15}$ Geriatric scales often combine cognition, behavior and activities of daily living measuring the global extent of decline but do not discriminate specific behavioral syndromes, such as FLD or AD. The Neurobehavioral Rating Scale, ${ }^{21}$ which is designed to assess the sequelae of head injury is an observational scale also explores some frontal behavioral symptomatology. Most of the items are in other domains, however, decreasing the specificity of the inventory. Although the general behavioral inventories assess, to a certain extent, the range of behaviors encountered in demented patients, the items are not specific enough to distinguish between various types of dementias. Such inventories contain a few items that may be characteristic of each type of dementia and this diminishes their discriminatory power. On the other hand, specialized inventories aimed at a specific condition, such as those designed to assess depression, have been extensively used for diagnosis. $22-24$

The goal of a specific scorable scale for frontal lobe symptomatology was to support and operationalize the diagnostic criteria of FLD and to discriminate it from $\mathrm{AD}$ and depressive illness. A condition that may resemble FLD is a depressive or bipolar illness in a middle-aged individual, especially with disinhibition in the manic phase. The frontal lobes have been implicated in depression and bipolar illness. ${ }^{25}$ It would be unusual of the disinhibited manic behavior of a bipolar illness to appear progressive without the fluctuation of behavior and response to pharmacotherapy. Furthermore, a bipolar illness rarely onsets in late middle-age. A depressive illness was excluded by using the Cornell Scale ${ }^{24}$ and the Beck Depression Inventory ${ }^{22}$ in our FLD population, besides the clinical impression of absent sadness, suicidal ideation, the vegetative features of depression. We also had formal psychiatric assessment and gathered evidence of treatment failure with antidepressants before establishing the diagnosis of FLD. Neuroimaging confirmation of frontal lobe or focal atrophy is also important in borderline cases, ${ }^{26,27}$ and we obtained evidence of frontal lobe atrophy or pathology in all of our cases of FLD.

Recently, retrospective information using questions similar to ours were used to establish the clinical diagnosis of FLD or AD after autopsy with considerable success by the Manchester group. ${ }^{28}$ We only became aware of this study after we had already constructed our inventory and presented it. ${ }^{29}$ The differences between their study and ours were of interest. They found aggression a feature of AD and not FTD, but in our histories this appeared prevalent in the early stages of FLD (Table 1). Some of these differences were related to staging and the time of eliciting information. Aggression is a common feature of later stage AD. ${ }^{30}$ Therefore, a retrospective inquiry, which includes all stages of the illness may cause conflicting impression of the prevalence of personality changes. It must be emphasized aggression occurs early in FLD and late in AD and PPA, in our experience. The similarities between the two studies reflect the fact that the questions used in both are based partly on the Lund/Manchester consensus, which, in turn, reflects clinical experience. The replication of the discriminatory power using a similar inventory is encouraging and indicates that the behaviors are specific for FLD and, therefore, the test has high "face validity." Furthermore, it confirms that these patients are not restricted to a few centres.

Behavioral assessment of FLD has been attempted by examining patients directly, called the "Executive Interview" or "Exit." 31 Some of the items were designed to detect motor or cognitive perseveration, verbal intrusions, disinhibition, loss of spontaneity, imitation behavior, and utilization behavior, although the brevity of the examination may be a problem. Some items, such as "frontal release signs," echopraxia and utilization behavior, motor perseverations or intrusions ("the alien 
hand") are captured during the neurological examination in our clinic. The "Exit" did not distinguish between Alzheimer patients and dementia of the frontal lobe type alone. The use of the Mini-Mental Status Examination was more useful in the differential diagnosis, probably because their Alzheimer patients were more severely affected in certain cognitive domains which the MMSE measures. ${ }^{32}$ On the other hand, the total score on the FBI by itself acted as a discriminating variable between FLD, $\mathrm{AD}$, and DD in our study. The "primitive" or "frontal lobe" reflexes occurred infrequently in our series and this reflects the early stages of dementia where diagnosis is based on mainly behavioral symptomatology. Patients who are seen later or assembled from a primary pathological series may have more primitive reflexes or extrapyramidal features.

Logopenia appears frequently in FLD, although initially the speech may be normal. Verbal apraxia is also a feature of an aphasic component involving anterior structures in the brain. ${ }^{33}$ Verbal apraxia includes hesitancy, dysprosody substitutions, and omissions of initial consonants particularly, and at times stuttering behavior. Any of these may be used in the scoring of the FBI, although they tend to be late in the illness. When these symptoms are the presenting features without accompanying behavioral symptoms or dementia, they are aptly labelled primary progressive aphasia. ${ }^{34}$ Interestingly, the original examples of published series of FLD patients contain a high incidence of logopenia, aphasia and mutism. ${ }^{1,35}$ The Lund/Manchester consensus ${ }^{9}$ also includes the speech problems in its core list of features. On the other hand, striking frontal lobe symptomatology often appears in later stages of PPA. ${ }^{4}$ The FBI may be used in PPA, in addition to a specific language task, such as the Western Aphasia Battery (WAB).${ }^{10}$ It is only recently that the commonality of FLD and PPA has been recognized, although this is still not widely acknowledged. ${ }^{3,4}$ Nevertheless, the behavioral disorder is so predominant in the initial stages of FLD that the continuing clinical distinction from PPA at the beginning of the illness is useful, as long as the nosological relationship is kept in mind.

The length of administration of the FBI is approximately 1015 minutes, depending on the care-giver and the extent of behavioral disturbance. The examiner is encouraged to elaborate the questions if necessary, to elicit accurate and complete details of the target behaviors and to note other symptoms that may be recounted. This is why it was decided not to have the care-giver fill out the form and score it alone. The interpretation of the severity of each behavioral disturbance was elicited from the care-giver, with a choice of 4 score points frequently repeated. In this pilot study with FBI, the inventory was administered at times by the same person who obtained the patient's history. No discernable difference was observed when it was obtained by another interviewer, who was not aware of the history or the diagnosis. Formal interrater reliability will be carried out in the future.

The content and face validity of the items was ensured by selecting the most frequent symptoms on history of the FLD patients and matching them to the Lund/Manchester criteria. ${ }^{9} \mathrm{~A}$ behavioral inventory, such as ours, is dependent on the reliability of the care-givers and this should be taken into consideration at the time of scoring. If the history and the behavioral inventory are very discrepant, then confirmation by another relative might be helpful. The purpose of asking the questions, positively and negatively, is to avoid a response bias. Well-intentioned reticence or underestimation of certain behaviors may result in false negative inventories. A false positive inventory is much less likely, although in one of our cases an apparent positive bias or an exaggerated perception of abnormality by the spouse may have been engendered by marital difficulties. Some questionnaires are given to the care-giver to score and aim at specific behaviors, such as "was suspicious," "kept changing his mind" ${ }^{36}$ Although these questions appear simple on the surface, considering the complexity of behavioral disturbance and the variations among care-givers, obtaining an answer through an interview is often more reliable. Guidance and elaboration by the examiner will likely achieve a more accurate and realistic survey of the target behavior.

The advantage of the FBI is in its brevity, specificity, and its ability to discriminate FLD from AD and DD. The scoring quantitates the characteristic behavior disturbance item by item and allows the longitudinal study of the patients and possibly to use the FBI as an instrument in the evaluation of treatment. Frontal lobe dementias and the primary progressive aphasias together are probably the largest biologically and behaviorally definable groups of non-Alzheimer dementias outside vascular disease. FLD is estimated to be $13-25 \%$ of the degenerative dementias by centres originally separating the entity on pathological and clinical grounds. ${ }^{1,37}$ If one considers the estimated $10 \%$ incidence of $\mathrm{PPA}^{4}$ these entities may constitute as much as $25-30 \%$ of patients with dementia. Currently many of these patients may be still misdiagnosed as $\mathrm{AD}$ or labelled as atypical dementia. Some may carry a label of depression or bipolar illness and become chronically institutionalized bypassing specialized dementia clinics.

A specific frontal lobe inventory, such as the FBI, may be used in other conditions, as well as FLD. The FBI may be useful in exploring the behavioral and personality changes in vascular dementia and in head injury. So far, we have applied this diagnostic instrument mainly at early stages of FLD or FTD, but we are collecting data in later stages of the illness as well. We recommend to complement the FBI with established inventories for depression, neurological, neuroimaging, and neuropsychological examinations. Besides, being a screening instrument, our questionnaire can operationalize the entry criteria for research studies, by applying the cutoff point of 27 or 30 as a minimum score for FLD. Another use is the retrospective diagnosis of FLD and FTD in deceased patients in whom pathology is available, similar to the retrospective study by Barber et al., ${ }^{28}$ provided the stage of illness is considered carefully in the inquiry. The diagnostic validity and interrater reliability of this inventory will be confirmed in a wider population.

\section{ACKNOWLEDGEMENTS}

This study was supported by an Alzheimer's Society Grant, Ontario Mental Health Foundation, Grant \#OMH512. We thank Bonita Caddel for typing the manuscript and our colleagues for referring patients.

\section{REFERENCES}

1. Neary D, Snowden JS, Northen B, Goulding PF. Dementia of frontal lobe type. J Neurol Neurosurg Psychiatry 1988; 51:353-361.

2. Gustafson L, Brun A, Risberg J. Frontal lobe dementia of nonAlzheimer type. In: Wurtman RJ, Corkin S, Growdon J, RitterWalker E, eds. Alzheimer's disease. Advances in Neurology, Vol 51. New York: Raven Press, 1990; 51: 65-71.

3. Snowden JS, Neary D, Mann MA, et al. Progressive language disorder due to lobar atrophy. Ann Neurol 1992; 31: 174-183.

4. Kertesz A, Hudson, L., Mackenzie IRA., Munoz, DG. The pathology and nosology of Primary Progressive Aphasia. Neurology 1994; 44: 2065-2072. 
5. Neary D, Snowden JS, Mann DMA, et al. Frontal lobe dementia and motor neurone disease. J Neurol Neurosurg Psychiatry 1990; 53: 23-32.

6. Caselli RJ, Windebank AJ, Petersen RC, et al. Rapidly progressive aphasic dementia and motor neuron disease. Ann Neurol 1993; 33: 200-207.

7. Rebeiz JJ, Kolodny EH, Richardson EP. Corticodentatonigral degeneration with neuronal achromasia. Arch Neurol 1968; 18: 20-33.

8. Riley DE, Lang AE, Lewis A, et al. Cortical-basal ganglionic degeneration. Neurology 1990; 40: 1203-1212.

9. The Lund and Manchester Groups. Clinical and neuropathological criteria for frontotemporal dementia. J Neurol Neurosurg Psychiatry 1994; 57: 416-418.

10. Karbe H, Kertesz A, Polk M. Profiles of language impairment in primary progressive aphasia. Arch Neurol 1993; 50: 193-201.

11. Kertesz A. Focal atrophies: primary progressive aphasia, frontal lobe dementia and the Pick complex. In: Fazekas F, Schmidt R, Alavi A, eds. Neuroimaging of Normal Aging and Uncommon Causes of Dementia. The Netherlands: ICG Publications, 1995 (In press).

12. Shader RI, Harmatz JS, Salzman C. A new scale for clinical assessment in geriatric populations: Sandoz Clinical Assessment Geriatric (SCAG). J Am Geriatr S 1974; 22: 107-113.

13. Hersch EL, Kral VA, Palmer RB. Clinical value of the London Psychogeriatric Rating Scale. J Am Geriatr Soc 1978; 26: 348-354.

14. Schwartz GE. Development and validation of the Geriatric Evaluation by Relatives Rating Instrument (GERRI). Psychol Rep 1983; 53: 479-488.

15. Reisberg B, Borenstein J, Salob SP, et al. Behavioral symptoms in Alzheimer's disease: phenomenology and treatment. J Clin Psychiatry 1987; 48 (Suppl): 9-15.

16. Niederehe G. Trims Behavioral Problem Checklist (BPC). Psychopharmacol Bull 1988; 24: 771-773.

17. Mungas D, Weiler P, Franzi C, et al. Assessment of disruptive behavior associated with dementia: the Disruptive Behavior Rating Scales. J Geriatr Psychiatry Neurol 1989; 2: 196-202.

18. Baumgarten M, Becker R, Gauthier S. Validity and reliability of the Dementia Behavior Disturbance Scale. J Am Geriatr Soc 1990; 38: 221-226.

19. Drachman DA, Swearer JM, O'Donnell BF, Mitchell AL, Maloon A. The Caretaker Obstreperous-Behavior Rating Assessment (COBRA) Scale. J Am Geriatr Soc 1992; 40: 463-480.

20. Cummings JL, Mega M, Gary K, et al. The neuropsychiatric inventory: comprehensive assessment of psychopathology in dementia. Neurology 1994; 44: 2308-2314.

21. Levin HS, High WM, Goethe KE, et al. The neurobehavior rating scale: assessment of the sequelae of head injury by the clinician. J Neurol Neurosurg Psychiatry 1987; 50: 183-193.
22. Beck AT, Ward CH, Mendelson M, Erbaugh JK. An inventory for measuring depression. Arch Gen Psychiatry 1961; 4: 561-571.

23. Hamilton M. Development of a rating scale for primary depressive illness. Br J Soc Clin Psychol 1967; 6: 278-296.

24. Alexopoulos GS, Abrams RC, Young RC, Shamoian CA. Cornell scale for depression in dementia. Biol Psychiatry 1988; 23: 271 284.

25. Taylor $\mathbf{M}$, Abrams R. Cognitive dysfunction in mania. Compr Psychiatry 1986; 27: 186-191.

26. Neary D, Snowden JS, Shields RA, et al. Single photon emission tomography using $99 \mathrm{mTc}-\mathrm{HM}-\mathrm{PAO}$ in the investigation of dementia. J Neurol Neurosurg Psychiatry 1987; 50: 1101-1 109.

27. Miller BL, Cummings JL, Villanueva-Meyer J, et al. Frontal lobe degeneration: clinical, neuropsychological, and SPECT characteristics. Neurology 1991; 41: 1374-1382.

28. Barber R, Snowden JS, Craufurd D. Frontotemporal dementia and Alzheimer's disease: retrospective differentiation using information from informants. J Neurol Neurosurg Psychiatry 1995; 59: 61-70.

29. Kertesz A, Fox H, Davidson W. Clinical and behavioral criteria in the diagnosis of frontal lobe dementia. Neurology 1995; 45 (Suppl. 4): A273(\#405S).

30. Burns A, Folstein S, Brandt J, et al. Clinical assessment of irritability, aggression, and apathy in Huntington and Alzheimer disease. J Nerv Ment Dis 1990; 178: 20-26.

31. Royall DR, Mahurin RK, Cornell J. Beside assessment of executive cognitive impairment: The Executive Interview (EXIT). J Am Geriatr Soc 1992; 40: 1221-1226.

32. Royall DR, Mahurin RK, Cornell J. Bedside assessment of frontal degeneration: distinguishing Alzheimer's disease from nonAlzheimer's cortical dementia. Exp Aging Res 1994; 20: 95-103.

33. Kertesz A. Aphasia. In: Frederiks JAM, ed. Handbook of Clinical Neurology (Vol. 1/45): Clinical Neurology. Amsterdam: Elsevier Publishers, B.V., 1985: 287-331.

34. Mesulam MM. Primary progressive aphasia - differentiation from Alzheimer's disease. Ann Neurol 1987; 22: 533-534.

35. Gustafson L. Frontal lobe degeneration of non-Alzheimer type. II. Clinical picture and differential diagnosis. Arch Neurol 1987; 6: 209-223.

36. Molloy DW, McIlroy WE, Guyatt GH, Lever JA. Validity and reliability of the Dysfunctional Behaviour Rating Instrument. Acta Psychiatr Scand 1991; 84: 103-106.

37. Brun A. Frontal lobe degeneration of non-Alzheimer type. I Neuropathology. Arch Gerontol Geriatr 1987; 6: 193-208.

\section{APPENDIX I}

NAME:

AGE:

DIAGNOSIS :

DATE:

DURATION: CARE-GIVER: EXAMINER

\section{FRONTAL BEHAVIORAL INVENTORY (FBI)}

Explain to the care-giver that you are looking for a change in behavior and personality. Ask the care-giver these questions in the absence of the patient. Elaborate if necessary. At the end of each question, ask about the extent of behavioral change, and then score it according to the following: $0=$ none; 1 $=$ mild, occasional; 2 = moderate; $3=$ severe, most of the time.

1. Apathy: Has s/he lost interest in friends or daily activities?

2. Aspontaneity: Does s/he start things on his/her own, or does s/he have to be asked?

3. Indifference, Emotional Flatness, Does s/he respond to occasions of joy or sadness as much as ever, or has s/he lost emotional responsiveness?
4. Inflexibility: Can s/he change his/her mind with reason or does s/he appear stubborn or rigid in thinking lately?

5. Concreteness: Does s/he interpret what is being said appropriately or does s/he choose only the concrete meanings of what is being said?

6. Personal Neglect: Does s/he take as much care of his/her personal hygiene and appearance as usual? 
7. Disorganization: Can s/he plan and organize complex activity or is s/he easily distractible, impersisent, or unable to complete a job?

8. Inattention: Does s/he pay attention to what is going on or does $\mathrm{s} /$ he seem to lose track or not follow at all?

9. Loss of Insight: Is s/he aware of any problems or changes, or does s/he seem unaware of them or deny them when discussed?

10. Logopenia: Is s/he as talkative as before or has the amount of speech significantly decreased?

11. Verbal Apraxia: Has s/he been talking clearly or has s/he been making errors in speech? Is there slurring or hesitation?

12. Perserveration: Does $\mathrm{s} /$ he repeat or perseverate actions or remarks?

13. Irritability: Has s/he been irritable, short-tempered, or is s/he reacting to stress or frustration as s/he always had?

14. Excessive Jocularity: Has s/he been making jokes excessively or offensively or at the wrong time?

15. Poor Judgment: Has s/he been using good judgment in decisions or in driving, or has s/he acted irresponsibly, neglectfully or in poor judgment?

16. Inappropriateness: Has s/he kept social rules or has s/he said or done things outside what is acceptable? Has s/he been rude, or childish?
17. Impulsivity: Has s/he acted or spoken without thinking about consequences, on the spur of the moment?

18. Restlessness: Has s/he been restless or hyperactive, or is the activity level normal?

19. Aggression: Has s/he shown aggression, or shouted at anyone or hurt them physically?

20. Hyperorality: Has s/he been drinking more than usual, eating excessively anything in sight, or even putting objects in his/her mouth?

21. Hypersexuality: Has sexual behavior been unusual or excessive?

22. Utilization Behavior: Does s/he seem to need to touch, feel, examine, or pick up objects within reach and sight?

23. Incontinence: Has s/he wet or soiled his or herself? (excluding physical illness, such as urinary infection or immobility).

24. Alien Hand: Does s/he have any problem using a hand, and does it interfere with the other hand? (excluding arthritis, trauma, paralysis, etc.)

Total Score: 